\title{
Desiring the Truth and Nothing But the Truth
}

\author{
Christian Piller \\ University of York
}

Forthcoming in A Haddock, A Millar, D Pritchard, eds., Epistemic Value, Oxford University Press 2007 (or 2008).

What is it to be interested in truth? According to what I call the Standard View, the lover of truth wants to believe that $p$ if and only if ' $p$ ' is true. In this paper, I argue that the Standard View is incorrect.

In the first section, I sketch my views on two related questions: 'Why are we interested in truth?' and 'Is such an interest optional?' In section 2, I explain the Standard View, which builds on William James's Insight that our interest in truth has two aspects - we want to catch the truth and avoid false beliefs. I criticize the Standard View in sections 3-5 by rejecting the idea that wanting to believe that p only if $\mathrm{p}$ is part of what, intuitively, is being interested in truth. Wanting to believe that $\mathrm{p}$, if ' $p$ ' is true, however, is central to our idea of being interested in truth. This leaves me with the problem of how to accommodate James's Insight and I deal with this problem in sections 6 and 7. I suggest that a desire not to believe inconsistencies is another aspect of our interest in truth. I find support for my view in considering Chisholm's remarks on the interest in truth but I have to disagree with Ernest Sosa on these matters. 


\section{Some Background}

We are many things, one of which is, we are believers. We are also sons or daughters, philosophers, and physical objects, to name a few others. And we all want to do well. We know what it is to do well as, let us say, a son. When I ask myself what I should do as a son, I answer on the basis of concerns that relate in appropriate ways to my parents and I bracket all other concerns. Is the same true when I ask myself what I should do as a believer? Which concerns would be salient and which bracketed?

Compare the following question. What sort of concerns should one bring towards one's being a desirer? Let us consider a case of desiring badly. I do not desire well, if I want things, the wanting of which is disruptive in regard to other things, which are important to me. Wanting to remain in open spaces at all costs might be such a troublemaker. If this is correct, then doing well as a desirer does not bracket any concerns. The question 'What should I do as a desirer?' is, in this respect, on the same level as 'What should I do as someone who owns money?' In both cases all my concerns are relevant to one realm of activity, money spending in one and desiring in the other case. I think the same holds for how to do well as a believer.

Others might disagree. They can point to the following feature of beliefs. Beliefs, in contrast to desires, have correctness conditions. A belief is correct if and only if what one believes obtains or is true. This tells us something about what beliefs are. They are the mental states that have truth as their correctness condition. Does this help us to find out what it is do well as a believer? Do the correctness conditions for beliefs provide us with a nonnegotiable aim insofar as we are believers? 
Some philosophers, at least when judging from first appearances, say they do. 'To believe a proposition is to accept it with the aim of thereby accepting a truth', says David Velleman (2000: 251). According to Nishi Shah (2003: 470), ‘...to say that it is a conceptual rather than [as in Velleman's view] a metaphysical matter that truth is the standard for correctness of belief is to say that a competent user of the concept of belief must accept the prescription to believe that $p$ only if $p$ is true for any activity that he conceives as belief-formation'.

No one will deny that a belief is correct if true. What one can deny, however, is that correctness is by itself normatively significant. Let me explain. I am a wearer of shoes. It might well be a conceptual truth that the right place for the right shoe is the right foot. If I wear the right shoe on the left foot I wear it incorrectly. Sometimes this might well be a good idea. Suppose the kids love it and the inconvenience is negligible. If, as usual, I wear my shoes correctly, I do so not because it is the correct way to wear them. I do it because I want to look normal, walk comfortably and so on. There are standards of correctness, which are essential to some activity, which we do not or cannot escape from. None of this, however, can establish the normative significance of these standards of correctness. ${ }^{2}$

Are there other ways to bind ourselves to aiming at truth? When thinking about how I might do well as a believer, one plausible suggestion might be that I want to have beliefs that are helpful to me and to others. If, for example, you ask for the right way, and I want to help you, I need to know what the right way is. At least I need a true belief about it. A true belief about the right way is important because it is important to 
take the right way. If, however, I am set on taking a wrong way (due to, for example, ignorance or weakness of will) it will be bad for me to have a true belief about how best to pursue what, as a matter of fact, is wrong. ${ }^{3}$ Why, then, should I be concerned about truth?

The answer, in my view, is that we want to act well. In acting we are guided by our conception of the situation we face in which we act. We can only act well if our picture of this situation is accurate. Truth is important because we need truth in order to be able to act well. ${ }^{4}$

Jane Heal (1987/88: 97) says, 'The transparency of truth allows whatever valuable features there are in a situation or project to shine through but does not itself contribute anything of substantive value.' True beliefs are necessary to do well. Their value comes from their participation in valuable projects (which, Heal rightly emphasizes, need not make the value of true beliefs instrumental). If we pursued truth not in the context of such a valuable project, the promotion of correspondence between beliefs and facts, '... would be a project of the same shape as that of, say, providing a suitable gnome for every garden and a garden for every gnome, gnomes and gardens just not being at their best unless paired off' (Heal 1987/88: 103). We all, however, pursue worthwhile projects. Thus, we all need truth. What exactly is it that we want when we say we want the truth and nothing but the truth $?^{5}$

2. The Interest in Truth: James's Insight and the Standard View

Our interest in truth is an interest in being believers of truths. William James - and I 
will refer to this in what follows as James's Insight - claims that there are two sides to this interest. ${ }^{6}$ "There are two ways of looking at our duty in the matter of opinions, ways entirely different, and yet ways about whose difference the theory of knowledge seems hitherto to have shown very little concern. We must know the truth; and we must avoid error, - these are our first and great commandments as would-be-knowers; but they are not two ways of stating an identical commandment, they are separable laws."

What I call the Standard View accommodates James's insight by understanding our interest in truth as an interest in a bi-conditional. What we want is to believe that $\mathrm{p}$ if and only if $p$ is the case.

The Standard View: DES(Bp↔p)

We can separate the two conditionals.

Part 1: DES $(\mathrm{p} \rightarrow \mathrm{Bp})$

Part 2: DES $(\mathrm{Bp} \rightarrow \mathrm{p})$

The first part tells us to believe all truths (if we understand it as universally quantified). ${ }^{7}$ The second part tells us to believe no falsehoods. The first part is by itself insufficient to spell out our interest in truth. Someone who says yes to every question will not have missed any truth, but, intuitively, such a person will not have satisfied what we mean by an interest in truth. For all the true answers this person gives there will be many false ones. The second part is by itself also insufficient to account for what we mean by an interest in truth. Someone who believes nothing will, trivially, believe no falsehood. Taking the two parts together, however, looks much 
better. We want to believe all and only truths.

Above I switched freely between the bi-conditional formulation and its parts. The biconditional entails the Part 1 conditional. However, we deal here with propositions in the context of being desired. Thus, we ought to be cautious. I certainly do not want to claim that desire or rational desire is closed under obvious entailment. In its generality, such a view would be implausible (see Ross 1941). If I want a letter to be mailed, then, if rational desire were closed under obvious entailment, I would also want any disjunctive expansion of the thing I want. For example, I would also want that the letter be mailed or that it be burnt. Anything would then satisfy a desire of mine even burning the letter, I wanted to be mailed. Ross's observation explains why another move would also be illegitimate. We cannot, in general, move from a desire for a conjunction $\mathrm{A} \& \mathrm{~B}$ to a desire for one of its conjuncts. Again, we would have weakened the content of our desire. Complementary goods - such as a cigarette and a lighter, a car and a tank of petrol - illustrate the illegitimacy of such a move.

We ought to be cautious when using logical manipulations within a desire context. At this point, however, we are safe. Our interest in truth, James has said, has two parts. The bi-conditional formulation simply puts these two parts together.

Many philosophers endorse the bi-conditional formulation of our interest in truth. Paul Horwich (2006: 347) defends the following principle. "It is desirable to believe what is true and only what is true". Ralph Wedgwood (2002: 291) writes, "In this way then, it is plausible that the norm according to which, for every proposition $\mathrm{p}$ that one actually considers, one should believe $p$ if and only if $p$ is true $[\ldots]$ is indeed the 
fundamental epistemic norm". Marian David (2001: 152f.) writes, "Let us characterize the truth-goal as the goal of believing truths and not believing falsehoods. Using 'p' as an objectual variable ranging over propositions, we can abbreviate this as the goal of believing $\mathrm{p}$ if and only if $\mathrm{p}$ is true."

If there are critical voices, they find Part 1 of the bi-conditional, which says that we want to believe all truths, implausible. Such critics point to our limited capacities or simply to utterly uninteresting truths, like those one can gather from an old phone book. A norm to believe all truths, Pascal Engel (2002: 128) says, “... is absurd. I can certainly incur no obligation to believe anything whatsoever that is true". Engel continues, "A more adequate formulation of the norm of belief comes from the observation that the phrase 'belief aims at truth' indicates that it is the function of belief to reach true, rather than false, contents. ... So the idea is that we should believe only the things that we deem true. Then the norm, in ought form, for belief, is rather this: For any $p$, one ought to believe that $p$ only if $p$ (is true)."

Engel confuses me on two accounts. First, to believe those things that we deem to be true seems, as long as we do not know what the difference between deeming to be true and believing is, to be no substantive norm at all. ${ }^{8}$ Secondly, he seems to miss James's Insight. He endorses Part 2 of the truth aim but puts nothing in the place of the rejected Part 1.

I do not think that the existence of uninteresting truths points to a deep problem. Thus, it does not need anything 'deep' to solve it. I do not know anyone in Irkutsk. The entries in its local phone book are certainly of no interest to me. Nevertheless, I think 
of myself as being interested in truth. Not in any truth, obviously, but in the correct answers to questions that are of some concern to me. I will restrict a person's interest in truth to those propositions the person finds, in some way or other, interesting.

3. Why the Standard View is Incorrect

In this section, I want to raise four points which all speak against the Standard View of our interest in truth. They are all related and so it might be just one point in different guises. They all support the same conclusion. We have to reject Part 2 of the bi-conditional, which is the idea that we want to believe $p$ only if $p$ is true.

I will make use of a certain rational transition rule, which the following example illustrates. Planning a walk in Irkutsk, I want that if someone asks me something, this person speak English. Soon after I set off, someone indeed asks me something. I did not understand a word and I answer in English, hoping that this person would understand me. Wanting to be understood is what my initial desire has committed me to. For most desires with a conditional content, wanting if $\mathrm{A}$ then $\mathrm{B}$ and noticing $\mathrm{A}$ commits me to wanting B. ${ }^{9}$ Another example: I want that if Jim does not get the post, then John should. I hear that the appointment committee has already eliminated Jim. Thus, I hope John will get it.

In cases like these, the transition from a desire for a conditional and noticing the truth of its antecedent to a desire for the consequent looks rationally mandatory. Ross's point does not affect it. This transition does not involve a weakening of the desired proposition we start with, quite the contrary. Arguably, it moves from a disjunctive 
desire to a desire for one of the disjuncts, via realizing that the other disjunct does not obtain. This is certainly plausible. I want to marry Sue or Lou. Sue is married to someone else, I hear. So, I want to marry Lou.

In anticipation of a criticism, I want to weaken the transition rule. I might want that John gets the post, after Jim has been eliminated, because he is the second most deserving candidate. In terms of the candidate's merit, I rank Jim over John and John over all the others. Thus, in terms of merit, I want that if Jim does not get the post, John should get it. Thereby, I have qualified my desire. It is desire based on only one group of concerns. I will allow desire talk, even if by saying one desires something one only means that one desires something in respect to a certain group of concerns. In this example, the area of interest is fairness - appointing in accordance to merit. Although, in terms of fairness I want John to get the job, if Jim does not get it, fairness need not be my sole concern or what is most important to me in these matters. Suppose I do not want anyone new in the department (for whatever reasons), and that this desire to leave things unchanged is stronger than my desire to appoint by merit. Thus, what I overall want (or want in an unqualified sense) is that no one gets the job. Overall, I also want that if Jim does not get the job, no one else should get it. Nevertheless, in terms of fairness, I want that if Jim does not get the job John should. Fairness is important to me so I will have to agree that Jim's not getting the job is a reason for me to want that John get the job. I recognize this reason. However, it does not determine what I want overall. The reason provided by my qualified conditional desire is outweighed by my desire to appoint no one. Taking such cases into account, I want to weaken the rule of rational transition I explained above: Wanting if A then B and noticing that $\mathrm{A}$ commits me to wanting $\mathrm{B}$ or, at least, gives me a reason to want 
B. $^{10}$

With this qualification in place, I can now move closer to my target. Part 2 - the desire to believe $\mathrm{p}$ only if $\mathrm{p}-$ is, intuitively, not an interest in truth.

Point 1 Believing that something bad is going to happen to me is no reason to want it to happen.

What Part 2 says is that we want if we believe that $p$, then $p$. Suppose we know that we believe that $\mathrm{p}$. Then, by the transition rule introduced above, we seem to be committed to wanting that $\mathrm{p}$. At least, believing that $\mathrm{p}$ would be, given what is taken to be an aspect of being interested in truth, a reason for wanting $\mathrm{p}$. This is implausible. Suppose $\mathrm{p}$ is something bad. Does the fact that I believe something bad will happen to me, give me any reason at all to want it to happen? It seems not.

Generalizing Point 1 The expected bad is not made any better by having been expected. The unexpected good is not made any less good by having been unexpected. The expected (or unexpected) indifferent remains indifferent.

Whether I want $p$ to obtain depends on my evaluation of $p$. If $p$ is something good, then I want it, if it is bad, I do not want it, and if I care neither way, I will be indifferent towards $\mathrm{p}$. Whether I believe that $\mathrm{p}$ will occur does not make any difference to my evaluation of $\mathrm{p}$ - at least if things are, as they normally are. Here is an example. I like sunny weather; I do not like rain. The forecast, which I know is reliable, predicts rain and so I believe it will rain tomorrow. Suppose tomorrow I look 
out of the window. What do I see? Rain. The fact that I thought it would rain, does not make it any better, it seems. The expected bad is still as bad. Suppose I look out of the window and what do I see? Sunshine. Great, I think, what a nice surprise! The fact that I believed it would rain does not at all diminish my delight in the good weather. The unexpected good is not made any less good by having been unexpected.

Our interest in truth is only one of our interests. Thus, I have made room for qualified desires. I am happy to phrase Part 2 as follows. Epistemically speaking, what we want is if we believe that $\mathrm{p}$ then $\mathrm{p}$. Qualified desires, I have argued, create reasons. After Jim has been eliminated as a candidate I want, in terms of fairness, that John gets the job. If he does, this makes what for me is a bad outcome, namely that someone is appointed, slightly better. I did not get what I most wanted, namely that things remained unchanged, but at least the second-best candidate got the job. My desire for fairness could have been insulted even more. Thus, a qualified desire for truth should make an expected bad a bit less bad. However, my example shows that nothing like this takes place.

One could challenge my first point as follows. I seem to care a lot about the weather and only a little about truth. Thus, for me, the effect of having been right in my belief that it will rain is so small that it does not really show. Is it a good defence of an account of our interest in truth to belittle this interest? I do not think so. I answer this challenge as follows. 'I do not care a lot about the weather. You know how it is. Sunshine is nice. But I have to go to work anyway, so it does not matter so much what the weather is like. Nevertheless, this morning I realized with some regret that it was raining.' The thought that I expected rain plays, as far as I can see, no role in my 
evaluation.

If our interest in truth were really as small as the objection above makes it out to be, we should expect that it shows its effect when it is unchallenged. Consider something one is indifferent about. I am locked in a cell. I am bored. I am very bored. I start counting the bricks it took to build my cell. I count simply to fill my mind with something. I do not even concentrate on my task. I start counting again. Over 2000 bricks, I conclude. Much later, free again, I hear I was right, there were more than 2000 bricks. I do not care. I only counted because I was bored. The expected indifferent is not made any better by having been expected.

Point 2 Wanting to be right is not being interested in truth.

There are exceptions to what I just said. I do not care about the number of bricks that made up my cell. However, having miscounted in the past, I might be concerned about my counting abilities. Now it seems I would be glad if I hear from a reliable source that my idea about the number of bricks was actually correct. Although I do not care about the number of bricks, I care about getting things right. We understand such a concern. Similarly, for weather forecasts. Suppose I form my beliefs about tomorrow's weather not by listening to the forecast but by gut feeling. This is interesting. It would be an unusual (and useful) ability to have. I think I can do it. My reaction to tomorrow's weather will then be different from before. Suppose my gut feeling tells me that it will rain tomorrow. Seeing rain the next day, I think, 'Wow, I can really do it! Excellent!' I still prefer sunshine to rain but my desire to have an unusual epistemic ability is more important to me. Wanting to get it right outweighs 
my concern for good weather.

My point is that this is a special case. In such a case we move easily from the fact that one believes something to the desirability of what is believed. Such cases show us what it is to have a Part 2 concern. It is to want to be right. Another example: Suppose I spent all my life arguing for a certain theory T. A crucial experiment takes place. Of course, I want it to confirm my theory T. I want to be proven right because my reputation depends on the outcome of this experiment. Am I a man of remarkable insights or someone who has been chasing shadows all his life? I hope very strongly that $\mathrm{T}$ will be confirmed. Do I have what, intuitively, is a concern for truth and nothing but the truth? Certainly not.

If wanting confirmation for my beliefs is not a concern for truth, what is? Being concerned about truth, one would hope that the experiment is reliable. One would not care about whether the experiment confirms or refutes $\mathrm{T}$. One would want it to decide the question one is interested in. The person, however, who would reason from the belief that $\mathrm{p}$ and Part 2 of the alleged interest in truth to the desirability of $\mathrm{p}-$ the person who wants to be right - does not have this open-mindedness which, intuitively, is part of an interest in truth. I conclude that sometimes, for sure, we have good reasons to want to be right. Wanting to be right, however, is not the same, as being interested in truth.

Point 3 An example that illustrates both points

There are signs that you have a serious illness; it is an illness that has hardly a chance 
of being cured and only a small chance of being contained. At the moment, your symptoms are inconclusive. It might be something altogether harmless. Soon you will know more. Your doctor has done a test. It is very reliable, not a $100 \%$, but it will be strong evidence one way or the other. You are a tough person. You want your doctor to give you a straight answer. That is why, after all, you have done the test. You want to know what your state is, even if it is bad. Here is the order of preference for a tough person like you. 'H' stands for being healthy, 'B' for belief.

\author{
$\mathrm{S} 1: \mathrm{H} \& \mathrm{~B}(\mathrm{H})$ \\ S2: H\&B(not-H) \\ S3: not-H\&B(not-H) \\ S4: not-H\&B(H)
}

What do we learn from this preference order? The first thing we learn is that you prefer being healthy to being ill. Being healthy is being in state S1 or in S2, being ill is being in state $\mathrm{S} 3$ or in $\mathrm{S} 4$. $\mathrm{S} 1$ or $\mathrm{S} 2$ is preferred to $\mathrm{S} 3$ or $\mathrm{S} 4$.

The second thing we learn is that you are interested in truth. You are interested in truth in what to me is the only right way of being interested in truth. You prefer S1 to S2. If you are healthy, you prefer believing that you are healthy to believing that you are not healthy. If you are healthy, you prefer believing truly do believing falsely. Furthermore, you prefer S3 to S4. If you are ill, you prefer believing that you are ill to believing that you are healthy. If you are ill, you prefer believing truly to believing falsely. Whatever you are, healthy or ill, you prefer believing truly to believing falsely. The first part, preferring truth when healthy, is easy. Who wants to have to worry 
about something unnecessarily? The second part, preferring truth when ill, is hard. Some prefer to live in an illusion. They prefer S4 to S3. They rather do not want to know when afflicted by some bad. You are not like that. You want to face the facts whatever they are. You are interested in truth.

The third thing we learn is that you are not interested in being right. If you believe you are healthy, then you prefer being healthy to being ill. If you believe you are healthy, you prefer believing truly to believing falsely. You prefer S1 to S4. If, however, you believe you are ill, then you prefer being healthy to being ill. If you believe you are ill, you prefer believing falsely to believing truly. You prefer S2 to S3. Your health is more important to you than the reliability of the test. This is how things normally are with people like us. We can imagine special circumstances under which the preference between S2 and S3 will be reversed. You are old. Your life will come to an end whether you have this illness or not. The little extra time you would get if you did not have this illness is not your biggest concern. You want to have lived a meaningful life. Your life was devoted to develop this test. You could not bear it if it got things wrong. In these circumstances you want to be right, no matter what. Are you concerned for truth, as we normally understand it? I do not think so.

Part 1 of the standard bi-conditional view - to believe $\mathrm{p}$ if $\mathrm{p}$ is the case - is a correct account of our interest in truth. Your preference order satisfies Part 1. Part 2 of the standard bi-conditional view - that $\mathrm{p}$ be the case if one believes that $\mathrm{p}-$ is not part of a correct account of our interest in truth. Your preference order violates Part 2 because you, very reasonably, prefer S2 (wrongly believing that you are ill) to S3 (rightly believing that you are ill). 
We might describe the lesson of this example as follows. For every mismatch between beliefs and the world, there is a match that is preferred. This shows that you are interested in truth. What is not true, however, is that every match is preferred to every mismatch. This shows that you are not interested in being right.

In my view, this example shows that the Standard View is incorrect. Part 2 of the Standard View is simply not part of a concern for truth as we understand it. It is not a concern characteristic of a seeker and lover of truth; it rather is the concern of a person we call the dogmatist. A concern for truth requires a certain kind of openness towards the world. Let me believe whatever it is that is true. Part 2, however, contains a rather different demand. Whatever I believe let it happen! Let me be right. ${ }^{11}$

\section{An Objection Rejected}

People in the grip of Part 2 might object to my way of seeing things as follows. It is true that the preference of S2 over S3 shows a violation of the Part 2 concern. This violation occurs because, quite reasonable, health is considered to be more important than satisfying the Part-2 concern. The fact that a concern can be outweighed, however, does not show that one does not have it. In fact, it is quite plausible to say that, in a qualified sense, one prefers S3 to S2. Epistemically speaking, S3 is better than S2. Thus, the example does nothing to undermine the idea that Part 2 is an essential aspect of our interest in truth.

There is something right about this objection and there is something wrong about it. I 
agree, epistemically speaking, S3 is preferable to S2. However - and here the objection goes wrong - this does not show that we accept Part 2 of the Standard View. $\mathrm{S} 3$ is preferable to S2 because S3 satisfies Part 1 of the interest in truth, whereas S2 does not satisfy Part 1. There is something good about S2 - you are healthy - and there is something bad about S2 - you have missed a truth. There is something good about S3 - you have captured a truth - and there is something bad about S3 - you are ill. Because you prefer S2 to S3 you would trade off one good - having captured a truth - for another - being healthy. We do not appeal to Part 2 to explain these facts. Thus, it is incorrect to assume that the fact that S2 is better than S3 shows that we have (an outweighed) Part-2 concern.

Suppose you prefer S4 to S3. S3 contains one good - you believe something true. S4 contains no good. Why would you then prefer S4 to S3? You will have this preference if health and truth are not your only concerns. A further concern will come into play. Believing something positive about yourself is itself a good to you, independently of whether the positive thing actually occurs or not. Now beliefs offer different goods. One good is to believe truly; the other is to believe pleasantly. If one trades off the good of truth for the good of pleasure (or, rather, for the good of lack of anxiety), then one has, intuitively, abandoned one's concern for truth. ${ }^{12}$

Compare this trade-off - a trade-off between goods believing can bring - with the trade-off between health and truth. Someone who is willing to make the latter tradeoff thinks that there are greater goods than that which can come from believing. Insofar as believing is concerned, such a person might well want the truth and nothing but the truth. ${ }^{13}$ This is, in my view, the only reasonable form our interest in truth can 
take. Believing truly is then most important when it comes to the goods believing can bring. The goods of believing, however, are not all the goods there are. Health is more important than a true belief about one's health. It would be absurd to suppose that it is part of our understanding of being interested in truth that it excluded or trumped all other worldly concerns. Only a fool or a whole-hearted dogmatist would have such a structure of concerns. Only a fool would want, when comparing the goods of believing to all the other goods, the truth and nothing but the truth.

This completes my answer to the objection. First, I have shown that we do not need to appeal to Part 2, in order to explain the facts on which the objection builds. Secondly, I have distinguished between two different kinds of trade-off. One kind of trade-off relies only on the claim that truth is not our only concern. Such trade-offs are compatible with the idea that insofar as one's beliefs are concerned truth is the only thing that matters. Insofar as one's beliefs are concerned we want truth and nothing but the truth. The second kind of trade-off is a trade-off between different features of beliefs all of which some agent might regard as important. Someone whose interest in truth is captured by Part 1 will allow trade-offs of the first kind but not of the secondkind. In this sense, such an agent is fully committed to an interest in truth. To disallow trade-offs of the first kind would show a pathological interest in wanting to be right. If the objection were right, we would have such a pathological interest. In order not to make us look like fools, however, the pathological interest attributable to us if the objection were right is said to be overridden by other worldly concerns like the concern for one's health. I have argued that there is no reason to attribute such an interest to us as part of our interest in truth. I conclude (diametrically opposed to Engel) that Part 2 is absurd as a characterization of our interest in truth. Special 
reasons aside, no one should want things to turn out a certain way simply because he or she believes that this is the way they are going to turn out.

I have argued for the view that Part 1 captures an essential aspect of our concern for truth. Part 2, however, captures a different concern. Special circumstances have to be put in place in order to make a Part 2 concern legitimate. In any case, it is not part of a concern for truth. I have expressed this point by talking about different forms of openness. Being concerned for truth is being open to the world. Let me believe whatever it is that the world might throw at me. It is a concern for my beliefs which is specified by how the world is. Such a concern is of the form 'If the world is such and such, let me be such and such'. We express this concern by means of world-mind conditionals. Part 2, however, is a concern about the world, which is specified by reference to my beliefs. Let the world be such that it proves me right. Such a concern is of the form 'If I am such and such, let the world be such and such'. We express this concern by means of a mind-world conditional. ${ }^{14}$ Being interested in truth, is a selfcentred concern. I want to be a certain way, namely responsive to the world. Whereas the relation between the world and truth is symmetric - ' $p$ ' is true if and only if $p$ our concern for truth is a concern about us and not about the world. ${ }^{15}$

\section{Astounding Mistakes}

Hartry Field (2001: 120f.) says "What we desire is the infinite conjunction of all claims of the form ... 'I believe " $p$ " only if p'... There is no difficulty in desiring that all one's beliefs be disquotationally true". Why would I want all my beliefs to be true (in whatever sense)? I think bad things are going to happen to me and to you as well. 
Why would I want them to happen?

Michael Lynch (2004: 499) writes, "Nobody likes to be wrong. If anything is a truism, this is. And it suggests that we value believing the truth. ... Other things being equal, it is good to believe a proposition if and only if it is true.... For not only do I not want to live in a world where I am a brain in a vat, or deceived by a demon, or whatever, I also do not want to live in a world where I am not thus deceived, but believe that I am. That is, if such and such is the case, I want to believe that it is, and if I believe that it is, I want it to be the case. I can put this by saying that I want my beliefs and reality to be disposed in a certain way - I want my beliefs to track reality, to 'accord with how the world actually is' - which is to say I want them to be true."

Nobody likes to be wrong? I am pessimistic about the chances for peace in the Middle East. Everyone who shares my worries would, like me, want to be proven wrong. Lynch tells us that he does not want to be a brain in a vat. The reason for his dislike, however, is not that he believes that he is not a brain in the vat and that he cannot stand to get things wrong. That would be a rather shallow reason. Lynch, in contrast to Field, actually uses mind-world conditionals, he accepts the transition rule I have argued for and he endorses desiring the detached consequent. If I believe that the world is such and such, he says, then, because of my interest in truth, I want it to be such and such. Despite the absurdity being right on the surface, it still went unnoticed.

6. Rejecting Part 2 Creates a Problem: How Can We Accommodate James's Insight?

Part 1 says that we want to believe all the truths (or, after appropriate qualification, it 
says that we want to believe all the truths we are interested in). Part 2 says that we want to believe no falsehood. I have argued that Part 2 is not part of our interest in truth. Have I said that, sometimes, it is quite okay, even epistemically speaking, to accept a falsehood?

Take the following case, a person believes that $p$, but not-p obtains. If this is all we say about this case, then the agent has missed a truth, the truth of not-p obtaining and, thus, has failed to achieve his Part 1 desire for truth. Part 1 is sufficient to explain that this person did not do well. So, why did we think we needed Part 2 in the first place? Suppose that not-p obtains, a person believes that $\mathrm{p}$ but, furthermore, believes that not-p as well. This person has not missed a truth. Part 1 provides us with no handle to criticize this person in terms of having failed to fulfil his interest in truth, as far as we have explained this interest. Therefore, our explanation is incomplete. We need to add something to Part 1 in order to show why an agent who believes obviously inconsistent things has not satisfied what we would call his or her interest in truth.

We have come some way already. We know that Part 1 is an important part of our interest in truth. Now we need to exclude contradictory beliefs. So let us just do this and let us replace Part 2 with Part 2*.

Part1 DES $(\mathrm{p} \rightarrow \mathrm{Bp})$

Part2* DES not(Bp\&Bnot-p)

I have said earlier that logical manipulations within the context of desiring are dangerous. Especially, we ought not to manipulate by weakening the content of what 
is desired. Nevertheless, same manipulations will be acceptable. I suppose the following might well be. The content of Part2* 'not(Bp\&Bnot-p)' is the same as 'notBp-or-notBnot-p', which is the same as 'Bp $\rightarrow$ notBnot-p'. This is still clearly the content of a desire for consistency. Now we have to use a further rule. If one wants if $\mathrm{A}$ then $\mathrm{B}$ and one wants if $\mathrm{B}$ then $\mathrm{C}$, then one is committed to wanting if $\mathrm{A}$ then $\mathrm{C}$, and, if rational, will have this desire. Let us apply this rule to the Part 1 desire $\operatorname{DES}(\mathrm{p} \rightarrow \mathrm{Bp})$ and the manipulated Part $2 *$ desire $\operatorname{DES}(\mathrm{Bp} \rightarrow$ not-Bnot-p) and we get $\operatorname{DES}(\mathrm{p} \rightarrow$ not-Bnot-p). Let us replace the content of this desire with one if its logical equivalents, which we get by contraposition, and we get DES(Bnot-p $\rightarrow$ not-p). We could have started with $\mathrm{q}$ instead of $\mathrm{p}$ and have $\mathrm{q}$ fixed as not-p. If we had then replaced $q$ with not-p and eliminated double-negation, we got $\operatorname{DES}(\mathrm{Bp} \rightarrow \mathrm{p})$. This desire is familiar. It is the Part 2 desire we want to reject. Now it turns out that someone who has desires Part 1 and Part2* is, arguably, rationally committed to having the Part 2 desire. The problem is how can we introduce a desire for consistency without thereby committing ourselves to the absurd Part 2 desire ${ }^{16}$

\section{A Solution to the Problem}

A desire for truth is, I have argued, I desire to be a certain way. It focuses on how we and our minds work. It is not a desire about what the world is like. We do not demand of the world to match whatever we believe. We demand of us to catch whatever the world is like. Therefore, our interest in truth can only be captured by world-mind conditionals and not be mind-world conditionals. 
In my logical manipulation of the Part $2 *$ desire, I have relied on a truth-functional understanding of the conditional. I have understood if-then sentences on the truthfunctional model of material implication. One of the rules I have used, which is valid for material implication, is the rule of contraposition. We can move from 'If A then B' to 'If not-B, then not-A'. The validity of this rule would undermine the distinction between mind-world and world-mind conditionals. This distinctions, however, is crucial to a correct understanding of our interest in truth. Thus, we have to reject a truth-functional understanding of the if-then sentence I use to express our interest in truth. We have to understand this conditional in a way which disallows contraposition. $^{17}$

We could, for example, adopt Stalnaker's idea of a non-truth-functional account of the indicative conditional and explain its truth condition in terms of possible worlds. The following example motivates his account. ${ }^{18}$ If you strike the match, it will light. Suppose you strike the match. Then this sentence will be true if the match lights, false otherwise. The truth-functional and the non-truth-functional account agree. Suppose you do not strike the match. A false antecedent makes the conditional true on the truth-functional account. This, however, does not seem right. Suppose the match was wet. Then the sentence 'If you strike it, it will light' strikes us as false. Why? Because in the closest possible world, in which you strike the match, it will not light.

Stalnaker's account serves our purposes ideally because contraposition is not a valid rule for his conditional. The fact that the closest A-world is also a B-world, does not entail that the closest not-B world is also a not-A world. Being interested in truth means to want that one believes $\mathrm{p}$ if $\mathrm{p}$ occurs (for all interesting propositions $\mathrm{p}$ ). One 
wants that the closest p-world is a world in which one believes that $\mathrm{p}$. One also has the Part $2^{*}$ desire, i.e. one wants not to hold contradictory beliefs. What is not included in our interest in truth is a desire that the closest Bp-world is a p-world. Often we have no reason to want this and even if we do, it is not well described as an interest in truth, it is rather a case of wanting to be right. ${ }^{19}$

\section{Considering Other Proposals}

In the reminder of this paper, I want to consider the views of two philosophers whose views on these matters relate, in different ways, to the view I have presented here. Chisholm, I want to show, endorses my view. Sosa discusses the problem which led me to abandon Part 2 as an aspect of our interest in truth. He, however, does not draw the same lesson as I have drawn.

In his Theory of Knowledge, Chisholm (1977: 15) endorses James's Insight. "Each person, then, is subject to two quite different requirements in connection with any proposition he considers: (1) he should try his best to bring it about that if a proposition is true then he believe it; and (2) he should try his best to bring it about that if that proposition is false then he not believe it."

Chisholm's way of understanding our interest in truth has the following two parts.

$$
\begin{array}{ll}
\text { Part } 1 & \text { DES }(\mathrm{p} \rightarrow \mathrm{Bp}) \\
\text { C-Part } 2 & \text { DES (not- } \mathrm{p} \rightarrow \text { not-Bp) }
\end{array}
$$

If contraposition were valid, then Chisholm would defend the Standard View. Given 
contraposition, there is no difference between C-Part 2 and Part 2 of the Standard View. Chisholm, as always, is careful. He uses two world-mind conditionals to express the two parts of our interest in truth. Therefore, we are well justified in assuming that Chisholm would be very unhappy about contraposition, as it would undermine the distinction between world-mind and mind-world conditionals, which he took such care to obey. The two parts taken together show that in having inconsistent beliefs an agent fails to satisfy his or her desire for truth. Thus, Chisholm's formulation is fine. We only need to add emphasis that the conditionals involved are not truth-functional. ${ }^{20}$

Sosa (2002: 51) writes, "A way to be interested in the truth as such, then, is to be motivated by interest in a question... Someone who wants the answer to the question whether $\mathrm{p}$ wants this: $<$ If $\mathrm{p}$, then $\mathrm{B}(\mathrm{p})$; and if not-p, then $\mathrm{B}($ not-p) $>$. That is to say, one desires that if $p$, then one believes that $p$, and if not- $p$, then one believes that not-p. Again, to be motivated by the truth on a question is to be motivated to believe the correct answer; let the chips fall where they may."

Let us note this down. The interest in truth is given by two world-mind conditionals.

$$
\begin{array}{ll}
\text { Part } 1 & \text { DES }(p \rightarrow B p) \\
\text { S-Part } 2 & \text { DES (not- } p \rightarrow \text { Bnot- } p)
\end{array}
$$

One might wonder whether S-Part 2 adds anything to Part 1. As these desires hold for all (interesting) propositions $\mathrm{p}$, it does not seem to matter whether we deal with negated or unnegated propositions. (Interest in whether $\mathrm{p}$ brings with it an interest in whether not-p.) 
Consider someone who wants to believe that $p$ regardless of whether $p$ is the case. If $p$ is the case, the person wants to believe that $\mathrm{p}$. Thus, this person has a Part- 1 concern. If not-p is the case, the person also wants to believe that $\mathrm{p}$. This person is not interested in truth because she lacks the interest described in S-Part 2. ${ }^{21}$

There are two problems with this account. First, Sosa has a twofold account of our interest in truth. Nevertheless, his account fails to preserve James's Insight. An inconsistent believer might well satisfy both parts of Sosa's account. Someone who believes everything will miss neither a negated nor an unnegated truth. Secondly, Sosa takes the conditionals involved to be material implications. If that were so, they would not be robust world-mind conditionals and our problem with Part 2 of the biconditional formulation would also affect Sosa's account. ${ }^{22}$

Sosa (2002: 50) addresses this problem. "If we believe that a dear friend is terminally ill we would not want our belief to be true. What we want, therefore, is not the truth of the beliefs we do have. We want rather that we would believe $<$ p $>$ only if $<$ p $>$ were true. And from this it does not follow that we want to believe $<\mathrm{p}>$, nor does it follow that we want $\langle\mathrm{p}>$. Neither of these follow even on the assumption that we do believe $<\mathrm{p}>$ and that it is true that $\mathrm{p}$. What we desire is only that our beliefs are safe; for any given proposition, other things equal we would generally desire this: that we believe it only if it were true. Desire neither for the antecedent nor for the consequent is logically entailed by our desire for the conditional. Our general antecedent desire is only for the safety of our beliefs, whatever they may be." 
According to Sosa, we want that we would believe $\mathrm{p}$ only if $\mathrm{p}$ were true. Strictly speaking, Sosa is right that such a desire does not entail a desire for the consequent $\mathrm{p}$, even if one believes that $\mathrm{p}$. We are not dealing with an entailment relation, but with a rule of rational transition that applies when an agent notices that the antecedent of his conditional desire obtains. Is this rule still plausible, when we consider subjunctive conditionals?

Earlier I have suggested Stalnaker's theory of conditionals as a way to capture what we are interested in when we are interest in truth. This theory suggests a possible world semantics for both the indicative and the subjunctive conditional. Thus, if it is rational to move from a conditional desire for $\mathrm{p}$, given that one believes that $\mathrm{p}$, to a desire for $\mathrm{p}$ when one notices that one believes that $\mathrm{p}$, then this rule should hold for both conditionals. Suppose that I want that John would be here only if Jane were here as well. I notice John. Am I not committed by my desire for the conditional to want Jane to be here as well? The same, it seems to me, holds for the desire that our beliefs be safe. I want that I would believe $p$, only if $p$ were the case. I realize that I believe that $\mathrm{p}$. Does not my desire for this belief's safety commit me to want it to be true? The desire I am committed it to is a desire about the world and, as I have been arguing, it is not part of our interest in truth. Introducing subjunctive conditionals avoids contraposition. If, however, you start with a desire for a mind-world conditional, then the transition rule will bring you to want the world to be a certain way, whether the conditional was indicative or subjunctive..$^{23}$

\section{Conclusion}


Many philosophers endorse the Standard View. According to them, we can express our interest in truth in form of the bi-conditional to believe that $\mathrm{p}$ if and only if $\mathrm{p}$. I have argued that the second part of this bi-conditional, namely to believe $\mathrm{p}$ only if $\mathrm{p}$, is not part of being interested in truth. The Standard View is incorrect. Our interest in truth is given by the first part of the bi-conditional - to believe $p$ if $p$ (for all interesting propositions $\mathrm{p}$ ) - and by a desire to avoid inconsistent beliefs. Adding such a desire for consistency is one way to preserve James's Insight that our desire for truth has two aspects. One's love of truth is a love of our responsiveness to what the world is like. It contrasts with wanting to be right, which is to love the world for being the way we take it to be. ${ }^{24}$

\footnotetext{
${ }^{1}$ Similarly Wedgwood (2002), who argues for the normative significance of truth on the basis that truth is the standard of correctness for beliefs. Velleman's position is, actually, more complex. He allows that a person might want to have a belief independently of its truth and, thus, lack any interest in truth. See Velleman (1996: 184-188), where he argues that belief will still be regulated by a teleological mechanism with the truth aim, and that a person's lack of interest in truth is a second-order interest relating to the truth-regulated mechanism.

${ }^{2}$ This, by no means, is meant to decide issues about the normative status of the aim of having true beliefs. I only want to say that the existence of correctness conditions does not by itself decide the normative issue. The same point is made in Shah (2003: 458) and Wedgwood (2002: 268f.) is also sensitive to this issue.

${ }^{3}$ Compare Moore's $(1907 / 08,173)$ example of the slow watch, which makes a man miss a train. This turns out to be a good thing, as the train will be involved in an accident. Given that we already have got something wrong - the train will make it safely to its destination - further mistakes might prove useful. (And who could think of himself as never getting anything wrong?) Weakness of will, by contrast, shows that true beliefs might be harmful even under conditions of full information.

${ }^{4}$ On this picture of action, we do not act well when we achieve our (worthwhile) ends by luck. Voluntary action, Aristotle argues, requires knowledge of an action's particulars, which are who is doing it, what one is doing, about what or to what one is doing it, sometimes also what one is doing it
} 
with, for what result and in what way. See Aristotle's Nicomachean Ethics Book III, chapter 1.

${ }^{5}$ Other philosophers hold truth in even higher regard. Plato says in the Laws (5.730c), 'of all things good, truth holds the first place among gods and men alike'. Aristotle famously starts his Metaphysics with the sentence 'All men by nature desire to know'. Man realizes his telos by being a knower. Brentano says that those things are good, which are loved with a love that we experience as being correct. Considering the love of truth and the hatred of error, we are, he says, immediately aware of the correctness of these attitudes. I mention Plato, Aristotle and Brentano to point to a stronger anchoring of our interest in truth. Its acceptability, however, depends on the credentials of the general philosophical views from which it springs. Heal's position is all I need to endorse to explain my project. Truth is important to us. What is it, then, that we care about?

${ }^{6}$ James $(1907,17)$ does not speak of our interest but of our duty to pursue truth. This difference will not matter for the concerns of this paper.

${ }^{7}$ Depending on where we put the universal quantifier, we get different conceptions of our interest in truth. If the universal quantifier is inside the desire operator, we have one desire to believe all truths. If it is outside we have a desire for each proposition to believe it if it is true. The relevance of this distinction is explored in David (2002), but will not affect our discussion.

${ }^{8}$ Later on (2002: 129), Engel seems to make this problem worse. He suggests the following for what we ought to be interested in: "For any $p$, believe that p only if, for all you know, $\mathrm{p}$ (is true)."

${ }^{9}$ There might be exceptions to this transition rule, e.g. when one desires a conditional simply because one desires the falsity of its antecedent. I will come back to such cases in the final section.

${ }^{10}$ This weakening allows for the desire for the conditional if A then B to be a qualified desire and not an overall desire. If the desire for the conditional is a qualified desire, it will still give me a reason to want $\mathrm{B}$, although, because of other things important to me, this reason might be outweighed.

${ }^{11}$ Point 4: If Part 2 were part of being interested in truth, we would have reasons to interfere in the world to make our predictions come out true. Suppose that, having behaved in epistemically unobjectionable ways, I have come to believe that $\mathrm{p}$ will happen. I can help it along a bit. Intuitively, my purely epistemic interest in truth does not give me any such reason. To help in bringing $\mathrm{p}$ about would, intuitively, be cheating.

${ }^{12}$ I do not claim that such a trade-off is unreasonable (nor do I claim the opposite). This question will have to be decided case by case. My question here is what our concern for truth is, not whether we 
should always have this concern.

${ }^{13}$ Other epistemic benefits a belief might have, like simplicity and explanatory power, come into play via the restriction of the interest in truth to those propositions an agent is interested in.

${ }^{14}$ The desire is, strictly speaking, a wide-scope desire. It is a desire for the conditional. I have argued for a certain transition rule, namely that we can move to a desire for the consequent on the basis of the desire for the conditional and knowledge of the occurrence of the antecedent. It is this transition rule that justifies the formulations I use above.

${ }^{15}$ I think that everyone shares the intuition that our interest for truth is a concern about us and not a concern about the world. This explains why proponents of the Standard View, when talking about Part 2, prefer the formulation 'Bp only if p' to 'If Bp, then p'. The first formulation makes it look like a self-centred desire. The second formulation makes it look like a world-centred desire. What, in my view, shows it to be a world-centred desire is that we can, via the transition rule introduced, infer from it a commitment to a world-centred desire.

${ }^{16}$ It has been pointed out to me that there are counterexamples to the transitivity rule I used above. Suppose I desire that if my house is on fire, I shall leave the house and that if I leave the house I shall lock the door. Nevertheless I will not want to lock the door of my burning house. Thus, sometimes, it seems, this rules, which looks acceptable in many cases, generates implausible results. Instead of refining the transitivity rule, we can derive the same problem without it. We can guarantee consistency by adding the following to Part 1 : DES(not-p $\rightarrow$ not-Bp). For every interesting $p$ that obtains one wants to believe it (Part 1) and one wants not to believe that $\mathrm{p}$ if $\mathrm{p}$ does not obtain (new part). In this case, the same problem arises in one step, as this new part can simply be transformed into the old Part 2 via contraposition.

${ }^{17}$ Humberstone (1992: 75) has argued that the difference between beliefs and desires comes from a difference in background intentions. "The controlling background intention in the case of belief is a conditional intention. [...] This intention can be described as the intention not to believe that $\mathrm{p}$, given that (or: in the circumstance that) not p." Humberstone thinks that to have this intention is constitutive of believing, whereas the intention to believe $\mathrm{p}$, given $\mathrm{p}$ is optional. For me, both are optional as I want to allow a case in which someone wants to believe that $\mathrm{p}$ independently of whether $\mathrm{p}$ or not-p is the case. More importantly, however, Humberstone agrees that any attempt to understand this conditional intention will have to disallow contraposition. 
${ }^{18}$ See Stalnaker (1975) and Edgington (2001) for details.

${ }^{19}$ Adams (1975) probabilistic account of conditionals would serve our purposes equally well and for the same reason - contraposition is invalid. We could also understand a desire to believe that $\mathrm{p}$ if $\mathrm{p}$ as the claim that believing that $p$, when $p$ is the case, is preferable to not believing that $p$, when $p$ is the case. Again, contraposition would not hold. See Humberstone 1992: 75.

${ }^{20}$ Foley (1987: 8) follows Chisholm.

${ }^{21}$ This is just one of the proposals Sosa investigates. I will come do a different account later on. In his article, Sosa's aim is more ambitious than mine. I simply want to understand our interest in truth. Sosa wants to understand the role our interest in truth plays in our intellectual lives. More in particular, he is interested in whether being interested in truth is a necessary condition for knowledge.

${ }^{22}$ In footnote 5 Sosa considers a subjunctive understanding of these conditionals. He rejects it for reasons concerning his more ambitious philosophical project. Someone, Sosa feels, might know some p that is good news for him without wanting that he believed not-p were not-p the case. To me this is a problem with the idea that an interest in truth has to play a role in an account of knowledge. It is not a problem of how to understand the interest in truth. Sosa might well have an opposing view on this matter.

${ }^{23}$ Sosa (2002: footnote 4) observes that if we understand the desire to believe that $\mathrm{p}$, if $\mathrm{p}$ as a material implication, then we will have this desire 'vacuously', whenever we desire the falsity of the antecedent p. Such a 'vacuously held' desire for the conditional is, however, not an interest in truth. This provides us with a further reason for the view defended here. The content of our desire for truth is not well captured by a material implication.

${ }^{24}$ Thanks to various audiences and various people.

\section{References}

Chisholm, Roderick M (1977), Theory of Knowledge, $2^{\text {nd }}$ edition, Englewood Cliffs: Prentice-Hall. 
David, Marian (2001). "Truth as the Epistemic Goal”, Knowledge, Truth and Duty, edited by M Steup, Oxford: Oxford University Press, 2001, 151-169.

Edington, Dorothy, "Conditionals", The Blackwell Guide to Philosophical Logic, edited by L Goble, Oxford: Blackwell, 2001, 385-414.

Engel, Pascal (2002). Truth, Chesham: Acumen.

Field, Hartry (2001). Truth and the Absence of Facts, Oxford: Oxford University Press.

Foley, Richard (1987). The Theory of Epistemic Rationality. Cambridge, Massachusetts: Harvard University Press.

Heal, Jane (1987/88). “The Disinterested Search for Truth”, Proceedings of the Aristotelian Society 88, 97-108.

Horwich, Paul (2006). "The Value of Truth", Nous 40.

Humberstone, IL (1992). "Direction of Fit", Mind 101, 59-83.

James, William (1896). "The Will to Believe" in his The Will to Believe and other Essays on Popular Philosophy, New York: Dover Publications, 1956, 1-31.

Lynch, Michael (2004). “Minimalism and the Value of Truth”, Philosophical Quarterly 54, 497-517. 
Moore, GE (1907/08). “Professor James's Pragmatism”, Proceedings of the Aristotelian Society 8, 33-77, reprinted in William James, Pragmatism, edited by D Olin, New York: Routledge, 1992, 161-195.

Ross, Alf (1941). "Imperatives and Logic", Theoria 7.

Shah, Nishi (2003). "How Truth Governs Belief”, Philosophical Review 112, 447-482.

Soas, Ernest (2001). "For the Love of Truth?", Virtue Epistemology: Essays on Epistemic Virtue and Responsibility, edited by A Fairweather \& L Zagzebski, Oxford: Oxford University Press, 49-62.

Stalnaker, Robert (1975). “Indicative Conditionals”, Philosophia 5, 269-286.

Velleman, David (2000). “On the Aim of Belief”, in his The Possibility of Practical Reason, Oxford: Oxford University Press, 244-281.

Velleman, David (1996). “The Possibility of Practical Reason”, Ethics 106: 694-726.

Wedgwood, Ralph (2002). “The Aim of Belief”, Philosophical Perspectives 16, 2002. 